Young people with psychiatric disabilities are particularly disadvantaged when it comes to participating in vocational training or higher education or to seeking and maintaining employment. A review of the literature reveals that this is due to a number of factors, including low expectations by health professionals, stigma and discrimination, symptomatology and the lack of a clear responsibility for promoting vocational and social outcomes. A useful approach for occupational therapists to use is a recovery framework combining evidence-based employment and educational assistance with mental health care, provided in parallel with brief vocational counselling, illness management skills, training in stigma countering and disclosure strategies, context-specific social skills and skills in social network development.

It is concluded that there is an urgent need to link evidence-based vocational practices with quality mental health care, in order to restore hope among young people of ever realising their vocational goals and once again feeling included as valued members of society.

\title{
The Importance of Vocation in Recovery for Young People with Psychiatric Disabilities
}

\author{
Chris Lloyd and Geoff Waghorn
}

\section{Introduction}

All community members have the right to work in suitable conditions, which reflect equity, security, human dignity and respect. Work is important to the mental health and wellbeing of individuals through providing opportunities to develop self-efficacy and self-esteem, key elements in Maslow's (1943) hierarchy of human needs. It is an aspect of life that provides economic security, valued personal roles, social identity and opportunities for individuals to contribute meaningfully to their local community. Benefits associated with work include structuring time and routine, social contact, collective effort and purpose, social identity and status, personal achievement and regular activity and involvement (Harnois and Gabriel 2000, Boardman et al 2003). Access to meaningful work facilitates economic and social participation in society. Opportunities for workforce participation, which contributes to a sense of social connectedness, are considered critical to the mental health and wellbeing of individuals, organisations, communities and nations (Morrow et al 2002).

Continuing experiences of social disadvantage can have significant effects on mental health and wellbeing (Morrow et al 2002). People with psychiatric disabilities are among the most disadvantaged groups in society and can face lifelong exclusion from the workplace, often experiencing difficulties in achieving the basic right to work (Harnois and Gabriel 2000). People with psychiatric disabilities are sensitive to the negative health effects of unemployment and the associated loss of structure, purpose and roles and diminished sense of personal identity (Boardman et al
2003). Despite the negative implications of mental illness for employment, work can be essential for maintaining mental health and wellbeing and for promoting recovery from mental illness. Work is also linked to opportunities for social inclusion in the wider community and provides an important means by which people with psychiatric disabilities can participate actively in society.

The United Kingdom based Social Exclusion Unit has identified some reasons why psychiatric disability leads to and reinforces social exclusion. These include: (1) stigma and discrimination, (2) low expectations by mental health practitioners, (3) the lack of a clear responsibility for promoting vocational and social outcomes, and (4) barriers to engaging in the community and with accessing basic services (Office of the Deputy Prime Minister [ODPM] 2004). To reduce social exclusion, people with psychiatric disabilities need opportunities to participate in the usual life activities and the common experiences available in their local community (Corrigan 2003). Participation in mainstream work, training and education is therefore important for providing the everyday socially valued roles necessary for enhancing the social integration and economic participation of people with psychiatric disabilities.

This paper examines:

- Barriers to employment among young people with psychiatric disabilities

- Early intervention and vocational assistance

- Recovery concepts

- The importance of work in recovery

- Steps to facilitate vocational recovery. 


\begin{tabular}{|c|c|c|c|c|}
\hline People aged 15-64 years & $\begin{array}{c}\text { Not in } \\
\text { the labour } \\
\text { force }(\%)\end{array}$ & $\begin{array}{c}\text { Looking for } \\
\text { work (\%) }\end{array}$ & $\begin{array}{c}\text { Employed } \\
\text { part time or } \\
\text { full time }(\%)\end{array}$ & Source \\
\hline \multicolumn{5}{|l|}{ Healthy Australians (no long-term } \\
\hline health conditions or disability). &. .19 .9$. & ....6.3. & $\ldots 73.8 \ldots$ & ....ABS (1999), Waghorn et al (2004a). \\
\hline Anxiety disorders (ICD-10) & $\ldots 47.1 \ldots$ & $\ldots \ldots . .7 .5$. & $\ldots \ldots .45 .4 \ldots .$. & ....ABS (1999), Waghorn and Chant (2005).. \\
\hline Depression (ICD-10, excluding postnatal) & $\ldots 56.4 \ldots \ldots$ & $\ldots . . . . .7 .4 \ldots$ & $\ldots \ldots .36 .2 \ldots \ldots$ & ....ABS (1999), Waghorn and Chant (2005) ...... \\
\hline \multicolumn{5}{|l|}{ Bipolar affective disorder (DSM-III-R), } \\
\hline most with psychotic features ................. & $\ldots 61.8 \ldots$ & $\ldots . . .4 .5 \ldots$ & $\ldots .28 .0 \ldots$ & ....Jablensky et al (1999), Waghorn et al (in press-a)...... \\
\hline Psychotic disorders (DSM-III-R). & $\ldots 75.2 \ldots$ & .....3.7. & $\ldots 21.1 \ldots$ & ....Jablensky et al (1999), Waghorn et al (2002)... \\
\hline Schizophrenia (DSM-III-R)... & $\ldots 80.7 .$. & $\ldots 3.0$ & $\ldots .16 .3 \ldots$. & ....Jablensky et al (1999), Waghorn et al (2003)... \\
\hline
\end{tabular}

Note: This table updates a previous publication (see King et al 2006, p472); published with permission of the Australian and New Zealand Journal of Psychiatry. ABS $=$ Australian Bureau of Statistics.

\section{Literature review}

A review of work and recovery was conducted. Papers were identified through searching Medline, PsycInfo and Cinahl for the period 1994-2006. Search terms included supported employment, vocational rehabilitation, work, employment, supported education and recovery. In addition, the reference lists of papers were reviewed for other relevant publications.

\section{Barriers to employment}

Although the majority of people with psychiatric disabilities would like to work, they are confronted by a challenging number of internal, external and systemic barriers, which impede their employment opportunities and prospects. Recent Australian studies (see Table 1) have found extensive non-participation in the labour force among people with all categories of mental illness, including anxiety disorders. Hence, people with all diagnostic categories of mental illness could benefit from a greater participation in effective educational and vocational services.

Mallick et al (1998) found that financial resources, employment resources and vocational skills presented the greatest barriers to community integration. Financial resources included the money to meet financial obligations, such as rent, food and other daily expenses. Employment resources were described as employment opportunities and available resources to obtain and maintain employment. Vocational skills included the ability to perform the interpersonal and work-related activities required in a job, such as following instructions willingly, working with others to perform a group task, completing tasks quickly and accurately and complying with occupational health and safety regulations in the workplace.

Three types of barriers to employment specific to psychiatric disabilities have been identified (for example, Rutman 1994, Waghorn and Lloyd 2005). These are (1) the impact of mental illness on the person, (2) external barriers such as the nature of the labour market and the availability of suitable employment assistance and (3) other systemic barriers to employment.

\section{The impact of mental illness on the person as a barrier to employment}

Employment barriers result directly from the cognitive, positive, negative and disorganised symptoms of psychosis, from the side effects of antipsychotic, mood-stabilising and antidepressant medications, and from subsequent impairments to social skills, sense of self, personal confidence and self-efficacy (Anthony 1994, Rutman 1994). Additional barriers to employment can result from the disruptive episodic nature of the disorders and from the impact on self-esteem of any past negative experiences of stigma and unfair discrimination. Furthermore, the timing of illness onset can disrupt formal education and training, impede school-to-work transitions and damage the early stages of career path formation and the acquisition of work values, work ethics and core work skills. Examples of how mental illness causes barriers to employment and how these can be overcome by appropriate interventions are shown in Table 2 .

Mental illness can produce cognitive, perceptual, affective and interpersonal deficits, each of which may contribute to employment barriers (Rutman 1994). Of these, the cognitive deficits have more consistent association with unemployment (Tsang et al 2000, McGurk and Mueser 2003, McGurk et al 2003), reduced job tenure (Gold et al 2002) and poor work performance (Mueser et al 2001). Cognitive deficits can include problems with attention, sustained attention, memory and executive functioning (Lewis 2004). In addition, deficits in social cognition (Vauth et al 2004) are associated with impaired work-related social skills and may underlie the impaired social competence, which influences vocational outcomes (Tsang and Pearson 1996, Tsang et al 2000).

Other internal barriers to achieving vocational goals include unpredictable sleeping patterns, fear of failure, fear of relapse, lack of confidence in vocational abilities, difficulties with concentration and fear of resuming work after years of unemployment (Provencher et al 2002, Corrigan 2003). In addition, subjective experiences perceived to have an impact on work functioning (Waghorn et al 2005a) and self-efficacy for specific core work activities (Waghorn et al 2005b) have recently been found associated with current vocational status. 
Table 2. Examples of common barriers to employment among people with psychiatric disabilities

\begin{tabular}{|c|c|c|c|c|}
\hline Type of barrier & Examples of barriers & Impact on career paths & $\begin{array}{c}\text { Types of interventions } \\
\text { needed }\end{array}$ & Examples of interventions \\
\hline $\begin{array}{l}\text { The direct impact of } \\
\text { mental illness on } \\
\text { the person }\end{array}$ & $\begin{array}{l}\text { Cognitive, positive, } \\
\text { negative and disorganised } \\
\text { symptoms are often } \\
\text { associated with severe } \\
\text { mental illness. }\end{array}$ & $\begin{array}{l}\text { The typical age of onset } \\
\text { at } 10-30 \text { years means } \\
\text { that secondary and higher } \\
\text { education are often } \\
\text { disrupted. Suitable }\end{array}$ & $\begin{array}{l}\text { Evidence-based mental } \\
\text { health treatment and } \\
\text { community-based care. }\end{array}$ & $\begin{array}{l}\text { Assertive community treatment } \\
\text { and care using a strength-based } \\
\text { approach. Help with independent } \\
\text { living and setting personal } \\
\text { recovery goals. }\end{array}$ \\
\hline
\end{tabular}

education and career paths

may not form or may be permanently disrupted.

Support and education for families and carers.

Evidence-based open employment or evidence-based vocational rehabilitation.

Evidence-based supported education to enable participation in accredited vocational training and higher education.

\section{The nature of the labour market and the availability of suitable assistance}

\section{Forms of stigma}

Some employers are unwilling to employ people with a mental illness. This can be due to low menta health literacy or to employers being unaware of how a particular mental disorder can be successfully accommodated in their workplace.

Some industries and jobs have only full-time opportunities, require shift work, use overtime offer flexible hours of attendance.

The fluctuating nature of ongoing assistance is needed to maintain employment. Not all vocational services provided time-unlimited support.
Career goals formed prior to becoming ill have to be revised according to the requirements of particular industries and employers, and according to the feasibility of managing mental health issues in different work settings.

The non-availability of time-unlimited support can lead to premature job loss through problems arising at work, which are not easily solved by the person with a mental illness without help.

Rejection by such employers can erode self-esteem and self-efficacy for employment. Negative career experiences can disrupt hope of one day restoring a suitable career path.
Evidence-based open employment and evidence-based vocational rehabilitation.

Ongoing time-unlimited support, behind the scenes or on-site, as required.

Stigma countering and disclosure strategies can be planned in advance.
Education and support for families through the timely provision of information about mental illness, treatments and the availability of other services and supports in the community.

The Drake-Becker Individual Placement and Support (IPS) model of open employment.

Group-based or individual, on-campus or off-campus support, to choose a study programme, enrol and continue enrolment until course completion.

Career counselling, rapid commencement of job searching, and job sampling to help the person test his or her job preferences, and establish limits to the hours of attendance he or she can sustain at work.

The employment specialist meets with the worker on a regular basis away from the workplace to discuss work performance and relevant issues emerging or likely to emerge in the workplace.

The employment specialist identifies a work performance issue and a form of assistance or an accommodation to address it. Arrangements are made to discuss the problem and its possible solution with the supervisor.

At job entry, information can be provided to counter stigma and inform the employer about how the mental health condition restricts the hours that can be worked and the types of tasks that are most suitable. The strengths and abilities of the person can be highlighted and strategies for monitoring and maintaining work performance can be discussed. 


\begin{tabular}{|c|c|c|c|c|}
\hline Type of barrier & Examples of barriers & Impact on career paths & $\begin{array}{c}\text { Types of interventions } \\
\text { needed }\end{array}$ & Examples of interventions \\
\hline & $\begin{array}{l}\text { Some health professionals } \\
\text { do not really believe that } \\
\text { people with severe mental } \\
\text { illness can work successfully. }\end{array}$ & $\begin{array}{l}\text { These health professionals } \\
\text { may not disclose this belief } \\
\text { to their patients, but may } \\
\text { enact this belief passively } \\
\text { by not discussing or } \\
\text { encouraging participation } \\
\text { in vocational rehabilitation. }\end{array}$ & $\begin{array}{l}\text { Structural links between } \\
\text { treatment services and } \\
\text { employment services to } \\
\text { facilitate knowledge } \\
\text { transfer across } \\
\text { both sectors. }\end{array}$ & $\begin{array}{l}\text { An employment specialist could } \\
\text { be co-located within the } \\
\text { community mental health } \\
\text { team, to discuss opportunities } \\
\text { for all clients regularly and to } \\
\text { report back on employment } \\
\text { outcomes achieved. }\end{array}$ \\
\hline & $\begin{array}{l}\text { Past stigma experiences or } \\
\text { negative career experiences } \\
\text { can have a lasting impact } \\
\text { on people with a serious } \\
\text { mental illness. }\end{array}$ & $\begin{array}{l}\text { This may cause people with } \\
\text { mental illness to be afraid } \\
\text { of returning to work or to } \\
\text { have low self-efficacy with } \\
\text { respect to employment. }\end{array}$ & $\begin{array}{l}\text { Focus on the person's job } \\
\text { preferences and perceived } \\
\text { need for assistance. }\end{array}$ & $\begin{array}{l}\text { Assessment of self-stigma, } \\
\text { work-related subjective } \\
\text { experiences and work-related } \\
\text { self-efficacy can be incorporated } \\
\text { into the early stages of a } \\
\text { vocational assistance } \\
\text { programme. These may identify } \\
\text { additional avenues for assistance } \\
\text { that the person agrees would } \\
\text { be helpful and relevant. }\end{array}$ \\
\hline
\end{tabular}

\section{The nature of the labour market as a barrier to employment}

Educational attainment is a consistent predictor of obtaining employment in the Australian labour market (Waghorn et al 2003, Waghorn et al 2004a). However, most people with psychotic disorders work part time and few manage both formal study and employment simultaneously (Waghorn et al 2004b), a widely used career advancement strategy in the wider community. Although little is known about how labour market characteristics constitute barriers to employment, industries that can best accommodate the employment restrictions imposed by mental illness (MacDonald-Wilson et al 2003, Waghorn et al 2004a) are likely to provide the most suitable employment opportunities.

\section{Forms of stigma as systemic barriers to employment}

Other systemic barriers to employment include community stigma, internalised stigma, stigma among health and vocational professionals and workplace stigma. Community stigma and unfair discrimination are frequently reported by people with psychiatric disabilities (World Health Organization 2001) as adding to the difficulties of obtaining and retaining employment.

This situation is exacerbated by the fact that some people with mental illness endorse stigmatising beliefs about psychiatric disability. This internalised stigma (also known as self-stigma) affects the individual's self-perception and has the potential to have an impact on the success or failure of employment opportunities (Corrigan and Watson 2002, Caltruax 2003). The extent of past stigma experiences and reactions to those experiences can influence personal decisions about whether or not vocational goals are adopted. In addition, past stigma experiences may exert a strong influence on disclosure preferences throughout psychiatric vocational rehabilitation (Waghorn and Lewis 2002).

\section{Low expectations by mental health professionals}

Low vocational expectations by mental health professionals may limit the vocational prospects of people with psychiatric disabilities. Blankertz and Robinson (1996) believed that health professionals' low vocational expectations of mental health service consumers prevented the majority of people from receiving vocational rehabilitation and supported employment services. Mental health professionals often report that people with psychiatric disabilities have unrealistic work expectations and goals (Becker et al 1996). However, direct surveys of consumers have revealed mostly realistic and informed job preferences (Mueser et al 2001, Bond 2004).

Through examining programmes with low competitive employment outcomes, Gowdy et al (2003) found that the onus was often placed on individuals to bring up their interests in employment with the mental health service provider. In addition, service providers tended to emphasise prevocational programmes devoted to job preparation, did not pursue rapid assessment and immediate job search or immediate job placement, tended to capitalise on the service user's work motivation, had limited contact with vocational services, had little direct employer contact and provided minimal support to people once they obtained employment. Robdale (2004) asserted that occupational therapists needed to reclaim employment as part of the profession's core activity and to involve themselves in more vocational projects.

\section{Early intervention and vocational assistance}

The disruptive and disabling effects of first episode psychotic disorders may be exacerbated by the more general development life phase issues of mid to late adolescence and the early adulthood period. Most psychotic disorders first emerge during this critical developmental period in the lifespan and have an adverse effect on social and 
emotional wellbeing (Davis et al 2000). Major developmental challenges of early adult transition include individuating from the family; developing interests, hobbies and skills; discovering and experimenting with sexuality; forming and maintaining relationships; and moving to employment or further study (EPPIC 2001).

The onset of a severe mental disorder can threaten a sense of self and identity, destabilise valued goals and roles and degrade social status. Untreated psychosis can have severe effects on young people across social, psychological and biological domains (EPPIC 2001). A study conducted by Gould et al (2005) found that young people identified the loss of self and life dreams as key issues. The symptoms of psychosis appearing in adolescence are often the forerunner for what may be lifelong problems in mental health and social wellbeing (Davis et al 2000) and profound and lasting changes to psychosocial circumstances. Among the most deleterious and long lasting of these is the disruption to educational and vocational trajectories, often resulting in long-term unemployment, underemployment or unrealised career goals and educational potential.

Early intervention is seen as having the potential to produce better outcomes for people with psychiatric disorders. Effective early intervention offers the hope of restoring normal social and psychological development (National Early Psychosis Project Clinical Guidelines Working Party 1998). The goals of early intervention can and ought to include reductions in the following: disruption to the family; disruption to employment or education; the need for inpatient care; the need for high dose antipsychotic medication; the risk of relapse; the risk of suicide; and the total cost of treatment (EPPIC 2001). Gould et al (2005) suggested that it is important for occupational therapists to provide incremental opportunities for young people to be involved in occupations that are meaningful in order to remake the link between occupation and normalcy.

\section{Supported education}

Evidence-based supported education for people with psychiatric disabilities is not widely available, even though the evidence suggests that supported education ought to be a standard component of community mental health care (Waghorn et al 2004b). Returning to education can restore disrupted education and may be essential to establish or restore career paths. Many young people with mental illness can return to education with appropriate assistance and often formulate career plans during these years (Mowbray et al 1999). Returning to education can be a better long-term strategy than entry-level employment and may increase career prospects by adding skilled work with more status, responsibility and financial benefits. In addition, supported education can provide access to a stigma-free identity as a student rather than a mental health patient (Waghorn et al 2004b).

Supported education typically takes a rehabilitation approach by providing assistance, preparation and supports to people wishing to pursue secondary or post-secondary education and vocational training (Mowbray and Megivern 1999). It has also been suggested that supported education can improve the employment outcomes of people with psychiatric disabilities (Mowbray and Megivern 1999). This important link is supported by Waghorn et al (2003), who found a positive association between educational attainment and both current and durable employment in a nationally representative sample of people with schizophrenia. Evidence-based practices such as supported employment (Bond 2004, Shankar 2005) and supported education (Waghorn et al 2004b) are considered critical for the community reintegration of people with severe mental illness (Bond et al 2004).

\section{The need for individualised assistance to maintain employment or education}

Job retention is a major challenge for people with psychiatric disabilities (Xie et al 1997). There is consistent evidence that ongoing support strategies improve job retention (Bond 2004). Ongoing support provided by occupational therapists can take various forms and may include on-site job coaching, regular phone calls to employers to monitor work performance and the need for further workplace accommodations. Support may include job coaching behind the scenes, anticipating and troubleshooting any work-related problems that may arise and, when appropriate, regular visits to the workplace (Gowdy et al 2003). People with psychiatric disabilities readily acknowledge employment restrictions, including the need for ongoing support (Waghorn et al 2004a). The support can be tailored to individual preferences and to the needs of the employer. The intensity of the support can vary with the fluctuating nature of many psychiatric disorders and with the emergence of new challenges in the workplace, such as changing duties, co-workers or supervisors (Waghorn and Lewis 2002).

For people receiving supported education, similarly flexible forms of continuing support are required. Support may include information on enrolment requirements, assistance in obtaining financial aid, stress management, time management, student rights and information about resources and assistance for people with disabilities and health conditions (Mowbray et al 1999, Davis and Rinaldi 2004). Students also benefit from information on the support groups available, choosing a field of study, more effective study habits, choosing a job and scheduling classes (Mowbray et al 2001). Both education and employment service providers need to be highly accessible and willing to operate by assisting people in their home, workplace or educational facility (Corrigan 2003, Davis and Rinaldi 2004).

\section{The need to support and educate employers}

Ongoing support to employers may influence their hiring decisions positively. It is essential to educate employers about mental illness, address their fears and ignorance and ensure that they feel supported in their role of managing 
employees with psychiatric disabilities (Shankar and Collyer 2003, Shankar 2005). This is best approached by providing a workplace education programme rather than focusing specifically on individuals. Such a programme could include the topics of mental health in the workplace, managing stress and positive working relationships (Waghorn and Lewis 2002). In addition, facilitating communication between the employer and the person through routine workplace interactions is likely to help to reduce any stigma associated with inaccurate beliefs about psychiatric disabilities (Waghorn and Lewis 2002).

\section{Recovery concepts}

Recovery is defined as the process of overcoming symptoms, psychiatric disability and social handicap (Rickwood 2004). It involves a redefinition of the self, the emergence of hope and optimism, empowerment and the establishment of meaningful relationships with others (Resnick et al 2004). Recovery is oriented towards the reconstruction of meaning and purpose in one's life, the performance of valued social roles, the experience of mental health and wellbeing, and increasing life satisfaction. It means maximising wellbeing within the constraints that may be imposed by residual psychiatric symptoms. Best practice incorporates the provision of continuing care, comprising relapse prevention plans and rehabilitation, provided within a recovery orientation. The lived experience of the person with the psychiatric disorder is acknowledged and the goals include maximising the person's wellness and wellbeing along with that of the family (Rickwood 2004).

One of the primary goals of psychiatric rehabilitation is to help people with psychiatric disorders to recover (Corrigan 2003). Recovery-focused rehabilitation interventions typically promote the goals of community integration, improved quality of life, personal empowerment and recovery (Casper et al 2002). Practices that serve these goals and have an underpinning evidence base include individualised supports, consumer choice, skills training, supported employment, supported education, peer support and social network development (Casper et al 2002). Consumers, however, have not consistently specified access to socially valued roles as a necessary ingredient of definitions of recovery. A recent review by Andresen et al (2003) of 28 experiential accounts of recovery, consisting of 14 articles written by consumers and eight qualitative studies, concluded that while a return to expected roles was not considered necessary for recovery, the re-establishment of personal goals, taking personal responsibility and making one's own choices were consistent themes in consumer recovery concepts.

\section{The importance of work in recovery}

Having a reason to get out of bed and having something meaningful to do during the day are essential for the wellbeing of people with psychiatric disabilities. Work has an important role in recovery and many of the general goals of rehabilitation and recovery are best served by addressing the person's vocational aspirations (Corrigan 2003). The potential importance of work and study to recovery is recognised by Liberman et al (2002). These researchers developed an operational definition of recovery, which included a return to work or study as an essential dimension, with the added benefit of being capable of objective measurement. The operational criteria have been successfully tested in focus groups comprising clients, family members, practitioners and researchers. The inclusion of socially valued role functioning within an operational definition of recovery was endorsed by all stakeholders.

Vocational activities can contribute to the recovery process in two ways. First, through work being perceived as a means of self-empowerment and, second, through work promoting a sense of independent identity and self-esteem (Provencher et al 2002). However, when competitive employment is not a current goal, meaning and purpose can be sought via participation in other contributing roles as a partner, parent or carer, in education, self-development or voluntary work, or through other artistic, social or recreational activities in the community (Waghorn et al, in press-b). Occupational therapists use client-centred assessments, in which they determine the individual's abilities, problems, wishes and interests. They focus on the strengths of the person in order to motivate him or her to be involved in the intervention by building a programme of intervention on his or her wishes and interests.

\section{Facilitating vocational recovery}

\section{Initiating conversations about work and education}

It is important that occupational therapists initiate conversations about work and education in the early stages of involvement with the service. The availability of suitable employment programmes and supported education programmes can be discussed, along with the person's career aspirations (Gowdy et al 2003). This is best done using a strengths-based approach, with clear expectations of vocational recovery. The elements of this approach include identifying the person's interests, talents, abilities and resources; discussing current roles, responsibilities and mutual expectations of the rehabilitative relationship; and updating regularly details of interests, achievements and resources in the person's own words (Waghorn and Lewis 2002). People who have not worked for a year or more may fear employment and may underestimate or overestimate their capabilities. Occupational therapists may need to discuss any concerns associated with working and assist individuals to overcome their fears through encouragement and supported exposure and through appropriate work-related strategies (for example, Gowdy et al 2003). For people who need to complete high school, or who desire higher education or vocational training, education goals can be explored in relation to longer-term career interests. 


\section{Vocational counselling and assessment}

Brief forms of vocational assessments and person-centred vocational counselling can be used to narrow the available education and employment options. However, due to the impact of mental illness and the likelihood of career immaturity, extensive assessment of abilities and career interests are not warranted and do not predict outcomes any better than the person's own preferences (Bond 2004). Occupational therapists often work with clients in their natural environments, where it has been found that clients feel more confident to open up during the doing process (Whitcher and Tse 2004).

Career counselling can be brief and exploratory and can occur in parallel with more active forms of vocational assistance (such as job searching) in order to build on a person's current motivation and job preferences, while not delaying attainment of the primary employment goal (Bond 2004). Waghorn et al (in press-b) suggested using a multidimensional measure of socially valued role functioning in the early stage of vocational assistance. This measure is expected to help individuals in reviewing current role activities and in selecting opportunities within available role options. For instance, a person may express employment interest yet, when asked about other role activities, may reveal an existing ongoing commitment to care for children or an ageing person, an equally important role that may not currently allow sufficient time or energy to be diverted to vocational goals.

\section{Skills training}

People who lack sufficient interpersonal skills to get by in the workplace will experience difficulty in achieving their vocational goals. Occupational therapists use strategies that assist people to learn and use social skills, which are necessary for some people to take advantage of opportunities in their community. The findings from the study conducted by Mairs and Bradshaw (2004) suggested that life skills training approaches could reduce symptoms.

People need to be able to obtain information about vocational opportunities and to enquire about required skills, job openings or course availability, and frequently need to complete application forms (Roder et al 2001). People also need sufficient social skills for common workplace situations, such as asking questions during a job interview, talking with co-workers during breaks, cooperating with co-workers to perform a group task and checking instructions with a supervisor (Waghorn and Lewis 2002, Waghorn et al 2005b).

Coping skills that assist people to address unexpected blocks to the attainment of their goals can be taught (Corrigan 2003). People may experience such problems as the rejection of a job application or interpersonal difficulties with co-workers. Strategies used by occupational therapists that can be taught include stress management, relaxation training, work-related communication and problem solving (Roder et al 2001). Social skills are usually taught in a staged process, which includes being introduced to the skills, role rehearsal, video feedback and homework assignments (Lloyd et al 2004).
To enable the skills taught to generalise beyond the training context, people need to be able to practise their newly learned skills in a variety of venues away from the treatment setting. Homework activities are important, through requiring people to rehearse the new skills in a setting with different social demands (Corrigan 2003). The main caveat is that for people with education or employment goals, any prevocational or general rehabilitative training should not delay active vocational assistance (Bond 2004) and can be focused on the particular employment or educational context that the person is seeking (Tsang and Pearson 1996, Tsang 2001).

In addition, people may need training and support to access community resources. People require basic resources, such as income support, housing, access to transport and good mental and physical health care, which are critical both to promote positive mental health and to enable people to take up opportunities in the community (Corrigan 2003, ODPM 2004). Occupational therapists are able to explore the ways in which they can assist people to access community resources (Heasman and Atwal 2004). People with psychiatric disabilities often experience financial hardship and may need assistance with budget planning, income support and benefit entitlements, which if not addressed could affect vocational motivation adversely (Bond 2004).

\section{Intersectoral partnerships}

It is important that community mental health service staff, including occupational therapists, establish structural links with local disability employment services and educational institutions (Davis and Rinaldi 2004). According to Davis and Rinaldi (2004), clients attaching a high priority to work and the social inclusion policy agenda highlighted the advantages of the involvement of occupational therapy in the vocational rehabilitation process. In addition, the most successful services integrate mental health care with employment assistance, an approach that has been shown to outperform brokered arrangements (Bond 2004). Intersectoral partnerships can also be used to help people to explore community opportunities. The incorporation of evidence-based practice within vocational rehabilitation into the community mental health team has led a shift from a purely medical outcome to a social outcome of gaining employment, education or voluntary work (Davis and Rinaldi 2004).

\section{Network development}

People with psychiatric disabilities usually have small social networks, which lack stability and reciprocity in relationships (Shankar and Collyer 2003, Heasman and Atwal 2004). The availability of supports can positively influence employment (Shankar and Collyer 2003) and educational outcomes (Mowbray et al 2001). Any interventions provided by occupational therapists can be complemented by interventions that strengthen and support the individual's social network. Social support helps the person to meet basic needs for affection and 
affiliation (Corrigan 2003) and facilitates a sense of belonging in his or her community. This can be achieved by improving people's opportunities for community participation by increasing access to education, volunteering, employment, arts and leisure (Black and Living 2004, Davis and Rinaldi 2004, Heasman and Atwal 2004, ODPM 2004). Occupational therapists may work with people who need assistance to take up activities of interest in mainstream settings, in addition to any activities provided by support groups. Supportive social networks can promote a sense of wellbeing, help to develop social confidence and encourage greater access to educational and employment opportunities.

\section{Conclusion}

The challenge for occupational therapists is to find ways to combine sensibly evidence-based practices from the mental health care, the early intervention and the specialised employment and supported education domains. Only then can they offer hope to people with psychiatric disabilities for the attainment of a relatively normal life. Becoming a mentally restored person through clinical treatment and mental health care is neither sufficient nor socially just, because people in full remission without symptoms often fail to return to socially valued roles in the community. People need appropriately intensive and continuing assistance, which aims to restore the secondary disabilities associated with being denied socially valued role opportunities and through having a spoiled social identity. Using a recovery framework, mental health services can make a difference, provided that their efforts encompass rather than exclude vocational attainment as a realistic and appropriate goal for people with psychiatric disabilities.

The main implication for occupational therapists is that the traditional approach of providing community-based mental health treatment and care needs to continue. However, the traditional focus on prevocational skills training, life skills education or general rehabilitative programmes in the mental health setting, unlinked to any systematic efforts to restore vocational functioning, can no longer be justified. In other words, traditional rehabilitation activities must give way to evidence-based practices, especially when people express a preference for employment or a return to formal education. However, once an employment context is identified, or employment or education commences, various forms of skills training (for example, illness management at work and work-related social skills training) can be applied productively in a particular setting, leveraged by the person's vocational motivation and perceptions of relevance.

\section{Acknowledgement}

This paper is based on a keynote address delivered by the first author to the Early Intervention in Psychosis National Training Forum in Auckland, New Zealand, in 2005.

\section{References}

Andresen R, Oades L, Caputi P (2003) The experience of recovery from schizophrenia: towards an empirically validated stage model. Australian and New Zealand Journal of Psychiatry, 37, 586-94.

Anthony WA (1994) Characteristics of people with psychiatric disabilities that are predictive of entry into the rehabilitation process and successful employment. Psychosocial Rehabilitation Journal, 17, 3-13.

Australian Bureau of Statistics (1999) Survey of disability, ageing, and carers, Australia. Technical paper. Confidentialised unit record file 1998. Canberra: Commonwealth Government.

Becker D, Drake R, Farabaugh A, Bond G (1996) Job preference of clients with severe mental disorders participating in supported employment programs. Psychiatric Services, 47, 1223-26.

Black W, Living R (2004) Volunteerism as an occupation and its relationship to health and wellbeing. British Journal of Occupational Therapy, 67(12), 526-32.

Blankertz R, Robinson S (1996) Adding a vocational focus to mental health rehabilitation. Psychiatric Services, 47, 1216-22.

Boardman J, Grove B, Perkins R, Shepherd G (2003) Work and employment for people with psychiatric disabilities. British Journal of Psychiatry, 182, 467-68.

Bond G (2004) Supported employment: evidence for an evidence-based practice. Psychiatric Rehabilitation Journal, 27, 345-59.

Bond G, Salyers M, Rollins A, Rapp C, Zipple A (2004) How evidence-based practices contribute to community integration. Community Mental Health Journal, 40, 569-88.

Caltruax D (2003) Internalised stigma: a barrier to employment for people with mental illness. International Journal of Therapy and Rehabilitation, 10, 539-43.

Casper E, Oursler J, Schmidt L, Gill K (2002) Measuring practitioners' beliefs, goals, and practices in psychiatric rehabilitation. Psychiatric Rehabilitation Journal, 23, 223-34.

Corrigan PW (2003) Beat the stigma: come out of the closet. Psychiatric Services, 54, 1313.

Corrigan PW, Watson AC (2002) The paradox of self-stigma and mental illness. Clinical Psychology: Science and Practice, 9, 35-53.

Davis C, Martin G, Kosky R, O'Hanlon A (2000) Early intervention in the mental health of young people. Adelaide: Australian Early Intervention Network for Mental Health in Young People.

Davis M, Rinaldi M (2004) Using an evidence-based approach to enable people with mental health problems to gain and retain employment, education and voluntary work. British Journal of Occupational Therapy, 67(7), 319-22.

EPPIC (2001) Case management in early psychosis: a handbook. Melbourne: EPPIC.

Gold JM, Goldberg RW, McNary SW, Dixon LB, Lehman AF (2002) Cognitive correlates of job tenure among patients with severe mental illness. American Journal of Psychiatry, 159, 1395-402.

Gould A, DeSouza S, Rebeiro-Gruhl KL (2005) And then I lost that life: a shared narrative of four young men with schizophrenia. British Journal of Occupational Therapy, 68(10), 467-73.

Gowdy L, Carlson L, Rapp C (2003) Practices differentiating high-performing from low-performing supported employment programs. Psychiatric Rehabilitation Journal, 26, 232-39.

Harnois G, Gabriel P (2000) Mental health and work: impact, issues and good practices. Geneva: World Health Organization and International Labour Organisation. 
Heasman D, Atwal A (2004) The Active Advice pilot project: leisure enhancement and social inclusion for people with severe mental health problems. British Journal of Occupational Therapy, 67(11), 511-14.

Jablensky A, McGrath J, Herrman H, Castle D, Gureje O, Morgan V, Korten A (1999) National survey of mental health and wellbeing. Report 5. People living with psychotic illness: an Australian study. Canberra: Mental Health branch, Commonwealth Department of Health and Aged Care.

King R, Waghorn G, Lloyd C, McLeod P, McMah T, Leong C (2006) Enhancing employment services for people with severe mental illness: the challenge of the Australian service environment. Australian and New Zealand Journal of Psychiatry, 40, 471-77.

Lewis $R$ (2004) Should cognitive deficit be a diagnostic criterion for schizophrenia? Journal of Psychiatry Neuroscience, 29, 102-13.

Liberman RP, Kopelowicz A, Ventura J, Gutkind D (2002) Operational criteria and factors related to recovery from schizophrenia. International Review of Psychiatry, 14, 256-72.

Lloyd C, Williams PL, Sullivan D (2004) Kick'n'On: helping young males kick back into life. Australian e-Journal for the Advancement of Mental Health, 3(2).

MacDonald-Wilson K, Rogers ES, Massaro J (2003) Identifying relationships between functional limitations, job accommodations, and demographic characteristics of persons with psychiatric disabilities. Journal of Vocational Rehabilitation, 18, 15-24.

Mairs H, Bradshaw T (2004) Life skills training in schizophrenia. British Journal of Occupational Therapy, 67(5), 217-24.

Mallick K, Reeves R, Dellario D (1998) Barriers to community integration for people with severe and persistent disabilities. Psychiatric Rehabilitation Journal, 22, 175-80.

Maslow AH (1943) A theory of human motivation. Psychological Review, 50, 370-96.

McGurk SR, Mueser KT (2003) Cognitive functioning and employment in severe mental illness. Journal of Nervous and Mental Disease, 191, 789-98.

McGurk SR, Mueser KT, Harvey PD, La Puglia R, Marder J (2003) Cognitive and symptom predictors of work outcomes for clients with schizophrenia in supported employment. Psychiatric Services, 54, 1129-35.

Morrow L, Verins I, Willis E (2002) Mental health and work issues and perspectives. Adelaide: Auseinet: Australian Network for Promotion Prevention and Early Intervention for Mental Health.

Mowbray C, Megivern D (1999) Higher education and rehabilitation for people with psychiatric disabilities. Journal of Rehabilitation 65, 31-38

Mowbray C, Collins M, Bybee D (1999) Supported education for individuals with psychiatric disabilities: long-term outcomes from an experimental study. Social Work Research, 23, 89-100.

Mowbray C, Bybee D, Collins M (2001) Follow-up client satisfaction in a supported education program. Psychiatric Rehabilitation Journal, 24, 237-47.

Mueser KT, Becker DR, Wolfe RS (2001) Supported employment, job preferences, job tenure and satisfaction. Journal of Mental Health, 10, 411-17.

National Early Psychosis Project Clinical Guidelines Working Party (1998) Australian clinical guidelines for early psychosis. Melbourne: National Early Psychosis Project, University of Melbourne.

Office of the Deputy Prime Minister (2004) Mental health and social exclusion. Wetherby: ODPM Publications.
Provencher H, Gregg R, Mead S, Mueser K (2002) The role of work in the recovery of persons with psychiatric disabilities. Psychiatric Rehabilitation Journal, 26, 132-44.

Resnick S, Rosenheck R, Lehman A (2004) An exploratory analysis of correlates of recovery. Psychiatric Services, 55, 540-47.

Rickwood D (2004) Pathways of recovery: preventing relapse. Canberra: Department of Health and Ageing.

Robdale N (2004) Vocational rehabilitation: the Enable Employment Retention Scheme, a new approach. British Journal of Occupational Therapy, 67(10), 457-60.

Roder V, Zorn P, Muller D, Brenner H (2001) Improving recreational, residential, and vocational outcomes for patients with schizophrenia. Psychiatric Services, 52, 1439-41.

Rutman ID (1994) How psychiatric disability expresses itself as a barrier to employment. Psychosocial Rehabilitation Journal, 17, 15-35.

Shankar J (2005) Improving job tenure for people with psychiatric disabilities through on-going employment support. Australian e-Journal for the Advancement of Mental Health, 4(1).

Shankar J, Collyer F (2003) Vocational rehabilitation of people with mental illness: the need for a broader approach. Australian e-Journal for the Advancement of Mental Health 2(2).

Tsang HWH (2001) Applying social skills training in the context of vocational rehabilitation for people with schizophrenia. Journal of Nervous and Mental Disease, 189, 90-98.

Tsang WH, Pearson V (1996) A conceptual framework for work-related social skills in psychiatric rehabilitation. Journal of Rehabilitation, 62, 61-67.

Tsang H, Lam P, Ng B, Leung 0 (2000) Predictors of employment outcome for people with psychiatric disabilities: a review of the literature since the mid-80s. Journal of Rehabilitation, 66, 19-31.

Vauth R, Rusch N, Wirtz M, Corrigan PW (2004) Does social cognition influence the relation between neurocognitive deficits and vocational functioning in schizophrenia? Psychiatry Research, 128, 155-65.

Waghorn G, Chant D (2005) Labour force activity by people with depression and anxiety disorders: a population level second order analysis. Acta Psychiatrica Scandinavica, 112, 415-24.

Waghorn G, Lewis S (2002) Disclosure of psychiatric disabilities in vocational rehabilitation. Australian Journal of Rehabilitation Counselling, 8, 67-80.

Waghorn G, Lloyd C (2005) The employment of people with a mental illness. Australian e-Journal for the Advancement of Mental Health, 4(2) (supplement)

Waghorn G, Chant D, Whiteford H (2002) Clinical and non-clinical predictors of vocational recovery for Australians with psychotic disorders. Journal of Rehabilitation, 68, 40-51.

Waghorn G, Chant D, Whiteford $H$ (2003) The strength of self-reported course of illness in predicting vocational recovery for persons with schizophrenia. Journal of Vocational Rehabilitation, 18, 33-41.

Waghorn G, Chant D, White P, Whiteford H (2004a) Delineating disability, labour force participation and employment restrictions among persons with psychosis. Acta Psychiatrica Scandinavica, 109, 279-88.

Waghorn G, Still M, Chant D, Whiteford H (2004b) Specialised supported education for Australians with psychotic disorders. Australian Journal of Social Issues, 39, 443-58.

Waghorn G, Chant D, King R (2005a) Work-related subjective experiences among community residents with schizophrenia or schizoaffective disorder. Australian and New Zealand Journal of Psychiatry, 39, 88-99. 
Waghorn G, Chant D, King R (2005b) Work-related self-efficacy among community residents with psychiatric disabilities. Psychiatric Rehabilitation Journal, 29(2), 105-13.

Waghorn G, Chant D, Jaeger J (in press-a) Employment functioning among community residents with bipolar affective disorder: results from an Australian community survey. Bipolar Disorders.

Waghorn G, Chant D, King R (in press-b) Classifying socially-valued role functioning among community residents with psychiatric disorders. American Journal of Psychiatric Rehabilitation.

Whitcher K, Tse S (2004) Counselling skills in occupational therapy: a grounded theory approach to explain use within mental health in New Zealand. British Journal of Occupational Therapy, 67(8), 361-68.
World Health Organization (2001) The World Health Report: 2001: Mental health: new understanding, new hope. Geneva: WHO.

Xie H, Dain BJ, Becker DR, Drake RE (1997) Job tenure among people with severe mental illness. Rehabilitation Counseling Bulletin, 40, 230-39.

\section{Authors}

Chris Lloyd, PhD, Division of Occupational Therapy, The University of Queensland, St Lucia, QLD 4072, Australia. Email: c.lloyd@uq.edu.au

Geoff Waghorn, PhD, Policy and Economics Group, Queensland Centre for Mental Health Research, School of Population Health, The University of Queensland, St Lucia, QLD 4072, Australia. 